\title{
Behavior of Metal Fractions with Depth in Soils of Children's Play Grounds within Owerri Metropolis, Imo State, Nigeria
}

\author{
Verla Evelyn Ngozi $^{1^{*}}$, Verla Andrew Wirnkor ${ }^{2}$, Egbuawa O. Irene $^{3}$ \\ I\&3Department of Environmental Technology, Federal University of Technology Owerri, Imo State, P. M. B. 1526, \\ NIGERIA \\ 2Department of Chemistry, Imo State University Owerri, Imo State, P. M. B. 2000, NIGERIA
}

*Corresponding Author: Verla Evelyn Ngozi, Department of Environmental Technology, Federal University of Technology Owerri, Imo State, P. M. B. 1526, NIGERIA

\begin{abstract}
A total of 36 soil samples from 9 playgrounds were collected in dry and rainy seasons at 0-5 cm, 5 $12 \mathrm{~cm}$ and 12-24 cm depths and then subjected to a six step sequential extraction procedure. Metal species of each in digests were analyzed by Perkin Elmer AAS, model A Analyst 400 and concentrations expressed in percent. Results showed metal fraction decreased with depth but most metals had fractions increasing after $12 \mathrm{~cm}$. There were higher mean values of metal concentrations in the dry season compared to the rainy season. Values for residual fractions were highest for all metals in dry season while cobalt concentrations were lower in rainy season. Therefore there is slow leaching of metals which mineralize at increasing depth due to changing condition with depth.
\end{abstract}

Keywords: Fractionation, metal exposure, Spatial, vertical, Species.

\section{INTRODUCTION}

Children of primary and nursing age bracket often engage in activities that make then ingest playground soil through their mouth ${ }^{1,2}$. These pica activities have health implications due to presence of contaminants in the soil. Therefore, if polluted with toxic heavy metals, surface soil could become a major concern of health risks to the public ${ }^{3,5}$. Researchers have linked child health to both type and cover of playgrounds and interesting literature exist on studies of children playgrounds in developing nations ${ }^{4,5}$. However such studies are yet to be conducted in Nigeria. Children' $s$ hands after playing contain elevated amount of metals and chromium (Cr) and arsenic (As) were largely adsorbed in children' $s$ hands from playgrounds soils ${ }^{6}$. As a result of their toxicity, persistence and bioaccumulative behavior and above all their mode of action in children, heavy metals constitute a group of serious pollutants in our natural environment ${ }^{7}$.

Hence, knowledge of spatial, vertical and seasonal variation in metal concentrations and species in playground soils could assist in controlling metal ingestion and accumulation in children. Here playtime is regulated according to these variations including nature of cover and other issues involved in playground construction.

Soils heavy metals have been known to vary with space, depth and time. Such variation could be useful for characterising pollutants contamination as well as modelling a wide range of environmental issues related to pollutant concentration. Heavy metal contaminations have received little attention and so metal variability with depth at playgrounds is almost non-existent.

Children are continuously being exposed to heavy metals by contact with surface soils of playgrounds and so variation of metal content at various depths could furnish useful information. This has been overlooked as most researches in the past on the heavy metals pollution in Nigeria have been concerned with the total heavy metal determinations ${ }^{8,9}$, while chemical fractionation of these soil metals have been rarely studied ${ }^{10}$. There has been no report on the depth variation of metals fractions in soils of children playgrounds.

The behavior of elements in the soil is a direct function of their chemical properties and this is currently being exploited to understand other metallic behaviors such as transport, reactivity in soil. In general biogeological behavior in different environmental matrix is better studied by speciation ${ }^{11}$. 
Surface soils may act as carriers and possible sources of metal pollution, since the mobility of these metals is such that they tend to stay in the upper layers except when leached without regard to type of soil. Moreover, these metals can be released by changes in climate or physicochemical properties of soils as well as rainfall. It is well known that natural soils contain significant concentration of iron ${ }^{12}$, ${ }^{13}$, at varying depths and space. Vertical and spatial variability of metals in most natural profiles gradually change from one horizon to the next. Urban soil profiles exhibit abrupt changes from one layer to another depending upon the constructional history of the soil. During construction topsoil may be scraped away and later filled thereby giving rise to distinct layers. This becomes even pronounced when the topsoil is from elsewhere. It has been observed that this lithologic change layer range from 6 to $35 \mathrm{~cm}$ in street side soil ${ }^{14}$.

This research presents results on a study carried out to determine $\mathrm{Mn}, \mathrm{Co}, \mathrm{Ni}, \mathrm{Zn}$ and $\mathrm{Cu}$ fractions of metals in soil through sequential extraction techniques with the aim of finding out the existence and trends of such special and vertical variation. This information could increase knowledge of present understanding of metals variation with depth and its contribution to ecotoxicology of these metals to in children's playgrounds

\section{Materials AND Methods}

\subsection{Sample Location}

Table1. Coordinates of sampling location

\begin{tabular}{|c|c|c|c|c|c|c|c|c|}
\hline \multicolumn{2}{|r|}{ Name of school } & DD & MM & SS & DD & MM & SS & ELEV \\
\hline $\mathrm{CSO}$ & Central school I & 05 & 29 & 00.4 & 007 & 01 & 48.8 & 73 \\
\hline $\mathrm{HEO}$ & Housing Estate Aladimma & 05 & 29 & 50.7 & 007 & 02 & 44.6 & 70 \\
\hline IKS & Ikenegbu PS & 05 & 29 & 27.0 & 007 & 02 & 23.2 & 74 \\
\hline $\mathrm{MNO}$ & Model P/S & 05 & 28 & 56.4 & 006 & 59 & 59.4 & 77 \\
\hline TSO & Township P/S I & 05 & 29 & 05.3 & 007 & 02 & 23.2 & 73 \\
\hline UPS & Urban P/S I & 05 & 28 & 59.8 & 007 & 02 & 01.5 & 73 \\
\hline WSP & Waterside P/S & 05 & 28 & 52.8 & 007 & 01 & 44.9 & 70 \\
\hline WBP & World Bank P/S & 05 & 29 & 09.3 & 007 & 00 & 19.9 & 82 \\
\hline SCP & Shell Camp P/S & 05 & 29 & 58.0 & 007 & 01 & 37.0 & 73 \\
\hline
\end{tabular}

\subsubsection{Sample Collection and Sample Pretreatment}

Soil samples were collected from pre-designated five points along a "W" shape 2 × 2 meters drawn on with particular reference to potential sources of metals within each playground. The soil samples were obtained with a hand auger from topsoil only (to a maximum depth of $25 \mathrm{~cm}$ ), that is the $A$ horizon, also avoiding the surface contaminants. The control (background) samples are topsoil obtained form a location remote from the metropolis at the outskirts of Owerri and far removed from the influence of industrial activities, transportation and heavy construction ${ }^{15}$.

\subsection{Chemicals and Reagents}

In the preparation of reagents, chemicals of high grade purity and distilled water were used. All glass wares were thoroughly washed with detergent solution followed by tap water and then distilled water was used for the rinsing. Throughout the course of this work, distilled water was used. Nitric acid $\left(\mathrm{HNO}_{3}\right)$ (suprapur), $\mathrm{HCl}$ (suprapur), sodium sulphate and potassium hydrogen carbonate were purchased from Merck (Fin lab. Owerri), while distilled water was used for heavy metals analyses; standard metal solutions for atomic absorption spectrophotometer were purchased from Fluka (Buchs, Switzerland). Appropriate calibration curves prepared in the same acid matrix with standard metal solutions for atomic absorption spectrophotometry were used for quantification.

\subsection{Speciation Procedure}

Nine playgrounds soils samples were subjected to a six step sequential extraction modified from Horsfall and Spiff, ${ }^{17}$ to carry out speciation of metals in the soil as follows. Water Soluble Fractions (F1): $1 \mathrm{~g}$ of the air dried soil sample (2mm sieve) were mixed with $10 \mathrm{ml}$ of de-ionized water with continuous agitation for 1 hour.

Exchangeable Phase (F2): The residue in (i) above is shaken at room temperature with $16 \mathrm{ml}$ of $1 \mathrm{M}$ $\mathrm{Mg}\left(\mathrm{NO}_{3}\right)_{2}$ at $\mathrm{pH} 7.0$ for 1 hour. Oxidized Phase (bound to organic matter) (F3): Residue form (ii) 
Behavior of Metal Fractions with Depth in Soils of Children's Play Grounds within Owerri Metropolis, Imo State, Nigeria

above $+10 \mathrm{ml}$ of $8.8 \mathrm{M} \mathrm{H}_{2} \mathrm{O}_{2}+6 \mathrm{ml}$ of $0.02 \mathrm{M} \mathrm{HNO}_{3}$ was shaken for $5+1 \mathrm{hrs}$ at $98^{\circ} \mathrm{C} .10 \mathrm{ml}$ of $3.5 \mathrm{M}$ $\mathrm{CH}_{3} \mathrm{COONH}_{4}$ was added as an extracting agent, the resulting mixture was then centrifuged. Acid Soluble Base (bound to carbonates) (F4): $25 \mathrm{ml}$ of $0.05 \mathrm{M} \mathrm{Na}_{2}$ EDTA was added to the residue in (iii) above ad shaken for $6 \mathrm{hrs}$ and centrifuged. Reducible Phase (bound to Fe- Mn oxides) (F5): Residue from (iv) above $+17.5 \mathrm{ml} \mathrm{N} \mathrm{H} \mathrm{O}+\mathrm{N} \mathrm{HCl} 0.1 \mathrm{M}+17.5 \mathrm{ml} \mathrm{CH}_{3} \mathrm{COONH}_{4} 3.5 \mathrm{M}$, shaken for $1 \mathrm{hr}$, centrifuged. Residential Phase (bound to silicates and deferential materials) (F6): Residue from (v) above was digested by using $\mathrm{HCl}-\mathrm{HNO}_{3} / \mathrm{HF}(0.35: 12 \mathrm{w} / \mathrm{v}$ solid solutions $)$ in acid digestion, Teflon cup. It was then dry ashed for $2 \mathrm{hrs}$ and evaporated, filtered and diluted to $50 \mathrm{ml}$ with double-distilled de-ionized water. After each successive extraction, the sample was centrifuged at $3000 \mathrm{rpm}$ for 15 minutes. The supernatants was then removed with pipette and filtered with Whatman No. 42 filter paper. The residue in each case was washed with de-ionize water, and made up to $50 \mathrm{ml}$ mark. The extracts were subjected to A Analyst 400 Perkin Elmer Absorption spectrophotometer.

\section{RESULTS AND DISCUSSION}

Table1. Some descriptive statistics of metal fractions, $F(\%)$ with depth (cm) in the dry and rainy season

\begin{tabular}{|c|c|c|c|c|c|c|c|c|c|c|c|c|c|c|c|c|}
\hline \multicolumn{17}{|c|}{ Dry season } \\
\hline & Metals & \multicolumn{3}{|c|}{$\mathrm{Mn}$} & \multicolumn{3}{|c|}{$\mathrm{Co}$} & \multicolumn{3}{|c|}{$\mathrm{Ni}$} & \multicolumn{3}{|c|}{$\mathrm{Cu}$} & \multicolumn{3}{|c|}{$\mathrm{Zn}$} \\
\hline Fraction & Depth & $0-5$ & $5-12$ & $12-24$ & $0-5$ & $5-12$ & $12-24$ & $0-5$ & $5-12$ & $12-24$ & $0-5$ & \begin{tabular}{|l|}
$5-12$ \\
\end{tabular} & $12-24$ & $0-5$ & $5-12$ & $12-24$ \\
\hline \multirow[t]{3}{*}{ FI } & Mean & 4.22 & 5.33 & 4 & 7.44 & 3.89 & 8.11 & 12.22 & 9.67 & 11.44 & 11.13 & 11.56 & 11.22 & 8.11 & 10.78 & 9 \\
\hline & Max. & 13 & 11 & 11 & 35 & 18 & 40 & 39 & 26 & 46 & 29 & 43 & 28 & 25 & 27 & 27 \\
\hline & Min. & 0 & 1 & 0 & 7 & 1 & 0 & 2 & 0 & 0 & 3 & 0 & 3 & 1 & 0 & 1 \\
\hline \multirow[t]{3}{*}{$\mathrm{F} 2$} & Mean & 12.89 & 8.56 & 8.44 & 8.78 & 6 & 3.11 & 9.67 & 12.22 & 8.44 & 17.11 & 12.78 & 18.33 & 23.44 & 18 & 22.78 \\
\hline & Max. & 28 & 28 & 23 & 31 & 17 & 19 & 26 & 34 & 20 & 34 & 24 & 37 & 42 & 33 & 44 \\
\hline & Min. & 1 & 0 & 0 & 2 & 0 & 0 & 0 & 1 & 0 & 5 & 4 & 6 & 9 & 1 & 7 \\
\hline \multirow[t]{3}{*}{ F3 } & Mean & 12.11 & 12.11 & 15.33 & 12.11 & 8.78 & 12 & 11.33 & 16.33 & 12.89 & 9.22 & 13.44 & 8.78 & 11.56 & 11.11 & 12.44 \\
\hline & Max. & 31 & 28 & 37 & 44 & 36 & 49 & 32 & 32 & 34 & 19 & 25 & \begin{tabular}{|l|}
19 \\
\end{tabular} & 24 & 16 & 26 \\
\hline & Min. & 1 & 1 & 0 & 1 & 0 & 0 & 3 & 4 & 0 & 3 & 6 & 0 & 4 & 5 & 3 \\
\hline \multirow[t]{3}{*}{ F4 } & Mean & 13 & 13.11 & 14.56 & 19.78 & 13.56 & 12.67 & 10.33 & 10.89 & 8.22 & 10.67 & 10.89 & 12.22 & 14 & 16.33 & 13.33 \\
\hline & Max. & 30 & 28 & 25 & 56 & 42 & 45 & 19 & 17 & 20 & 23 & 17 & 25 & 31 & 36 & 27 \\
\hline & Min. & 2 & 3 & 0 & 0 & 0 & 0 & 2 & 4 & 0 & 4 & 4 & 4 & 3 & 4 & 3 \\
\hline \multirow[t]{3}{*}{ F5 } & Mean & 18.44 & 11.11 & 18.56 & 16.67 & 23.33 & 14.44 & 9.67 & 14.67 & 12.67 & 12.22 & 15.11 & 12.33 & 13 & 17.44 & 12.56 \\
\hline & Max. & 35 & 26 & 32 & 30 & 3 & 28 & 28 & 45 & 37 & 21 & 31 & 26 & 32 & 40 & 37 \\
\hline & Iin. & 1 & 0 & 0 & 38.56 & 2 & 0 & 2 & 0 & 0 & 3 & 3 & 0 & 3 & 3 & 4 \\
\hline \multirow[t]{3}{*}{ F6 } & Mean & 39.33 & 49.78 & 39.44 & 68 & 44.44 & 49.67 & 46.67 & 36.89 & 46.33 & 40.11 & 36.56 & 37.11 & 31.33 & 26.33 & 29.89 \\
\hline & ax. & 70 & 76 & 98 & 12 & 79 & 88 & 62 & 16 & 87 & 52 & \begin{tabular}{|l|}
64 \\
\end{tabular} & 48 & 44 & 38 & 43 \\
\hline & Min. & 20 & 19 & 13 & & 9 & 10 & 29 & 12 & 16 & 25 & 20 & 22 & 11 & 14 & 11 \\
\hline \multicolumn{17}{|c|}{ Rainy season } \\
\hline & & \multicolumn{3}{|c|}{$\mathrm{Mn}$} & \multicolumn{3}{|c|}{$\mathrm{Co}$} & \multicolumn{3}{|c|}{$\mathrm{Ni}$} & \multicolumn{3}{|c|}{$\mathrm{Co}$} & \multicolumn{3}{|c|}{$\mathrm{Zn}$} \\
\hline & Depth & $0-5$ & $5-12$ & $12-24$ & $0-5$ & $5-12$ & $12-24$ & $0-5$ & $5-12$ & $12-24$ & $0-5$ & $5-12$ & $12-24$ & $0-5$ & $5-12$ & $12-24$ \\
\hline \multirow[t]{3}{*}{ FI } & Mean & 8.89 & 9.78 & 9.11 & 11.3 & 15.33 & 10.44 & 13.89 & 13.44 & 14.33 & 10 & 9.78 & 11.22 & 13.33 & 13.22 & 13.33 \\
\hline & Max. & 12 & 15 & 14 & 14 & 32 & 21 & 29 & 52 & 50 & 18 & 20 & 22 & 24 & 27 & 27 \\
\hline & Min. & 4 & 2 & 5 & 8 & 7 & 1 & 3 & 0 & 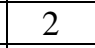 & 7 & \begin{tabular}{|l|}
5 \\
\end{tabular} & 5 & 4 & 4 & 4 \\
\hline \multirow[t]{3}{*}{$\mathrm{F} 2$} & Mean & 10.78 & 10.89 & 9.56 & 15.89 & 15.33 & 8.11 & 12.78 & 15.1 & 12.11 & 13.67 & 19.78 & 15.56 & 8.78 & 9.67 & 11.11 \\
\hline & Max. & 19 & 21 & 20 & 26 & 32 & 17 & 33 & 52 & 31 & 43 & 51 & 40 & 12 & 13 & 24 \\
\hline & Min. & 6 & 2 & 0 & 6 & 7 & 0 & 1 & 0 & 3 & 0 & 0 & 4 & 3 & 4 & 5 \\
\hline F3 & Mean & 10.89 & 10.67 & 15.33 & 15.33 & 15.78 & 13 & 8.78 & 8.11 & 10.33 & 11.67 & 8.11 & 10.78 & 18.44 & 17.56 & 17.56 \\
\hline & Max. & 18 & 25 & 46 & 42 & 30 & 19 & 28 & 23 & 30 & 23 & 23 & \begin{tabular}{|l|}
18 \\
\end{tabular} & 36 & 38 & 39 \\
\hline & Min. & 3 & 3 & 5 & 8 & 7 & 2 & 3 & 0 & 3 & 4 & \begin{tabular}{|l|}
0 \\
\end{tabular} & 5 & 5 & 3 & 6 \\
\hline F4 & Mean & 17.33 & 17 & \begin{tabular}{|l|}
16.33 \\
\end{tabular} & 14 & 7 & 17.22 & 11.78 & 11.67 & 11.89 & 14.22 & 14.7 & 13.67 & 9.22 & 12.11 & 13 \\
\hline & Max. & 31 & 36 & 29 & 26 & 31 & 26 & 36 & 44 & 32 & 24 & 24 & 26 & 18 & 25 & 27 \\
\hline & Min. & 5 & 4 & 7 & 5 & 0 & 9 & 2 & 0 & 3 & 7 & 5 & 6 & 2 & 4 & 4 \\
\hline F5 & Mean & 25.56 & 24.89 & 23.67 & 24 & 23.33 & 21.89 & 19.89 & 19.44 & 26.67 & 19.11 & 21.22 & 20.44 & 21.11 & 18.60 & 19.33 \\
\hline & Max. & 40 & 42 & 36 & 38 & 40 & 43 & 28 & 37 & 65 & 34 & 33 & 33 & 34 & 32 & 34 \\
\hline & Min. & 14 & 0 & 8 & 7 & 11 & 10 & 6 & 6 & 8 & 13 & \begin{tabular}{|l|}
13 \\
\end{tabular} & 14 & 10 & 8 & 10 \\
\hline F6 & Mean & 25.33 & 26.78 & 25.78 & 19.44 & 20.22 & 20.56 & 32.78 & 33.33 & 24.67 & 31.33 & 26.33 & 24.67 & 29.11 & 28.78 & 25.67 \\
\hline & Max. & 58 & 63 & 49 & 35 & 47 & 30 & 68 & 67 & 42 & 49 & 51 & 42 & 58 & 69 & 47 \\
\hline & Min. & 12 & 16 & 13 & 12 & 0 & 14 & 10 & 10 & 11 & 8 & 5 & 11 & 8 & 9 & 10 \\
\hline
\end{tabular}


Behavior of Metal Fractions with Depth in Soils of Children's Play Grounds within Owerri Metropolis, Imo State, Nigeria

Table 1 shows the mean, maximum and minimum concentrations of metals fractions at various depths for all five metals studied. Fractions of $\mathrm{Mn}$ at $5 \mathrm{~cm}$ were higher than for dry season. This could be due to increased solubility in soil moisture during the rainy season. This trend was exhibited by all metals. Minimum values of metals F1 fractions were observed at 5cm were as F6 fractions had highest values in the dry season.

\subsection{Water Soluble Fraction}

The water soluble metal fractions were lowest for most playgrounds in dry season and in some cases not detectable (MNO and CSO) at $5 \mathrm{~cm}$ in 2014. Also CSO, TSO for Co were undetectable. Cobalt had highest $\mathrm{F} 1$ fraction ( $35 \%$ at $\mathrm{HEO}$ ) at $5 \mathrm{~cm}$. The mean percent $\mathrm{F} 1$ fraction for all metals range from 4.22 to $11.56 \%$ at $5 \mathrm{~cm}$. It was observed that all five metals had F1 fractions that increase with depth.

Mn showed the generally low F1 fractions as can be seen on fig.1 where as $\mathrm{Ni}(46 \%)$ has the highest $F_{1}$ which occurred at $24 \mathrm{~cm}$. The $F 1$ fractions for all playgrounds with depth showed the following order of increasing values $\mathrm{Ni}>\mathrm{Cu}>\mathrm{Co}>\mathrm{Zn}>\mathrm{Nn}$. Metals exhibited highest values at $24 \mathrm{~cm}$ in the case of $\mathrm{Co}, \mathrm{Ni}$ and $\mathrm{Zn}$ while $\mathrm{Cu}$ and $\mathrm{Mn}$ showed highest water soluble fractions at $12 \mathrm{~cm}$ and $5 \mathrm{~cm}$ respectively. The water soluble fractions are perhaps most important in toxicity studies as they are readily absorbed and absorbed into children. It is therefore advantages that water soluble fractions were lowest for most $5 \mathrm{~cm}$.

Due to possible leaching the soluble fraction for $\mathrm{Co}, \mathrm{Ni}$ and $\mathrm{Zn}$ were low, while $\mathrm{Cu}$ and $\mathrm{Mn}$ showed highest water soluble fractions at $12 \mathrm{~cm}$ and $5 \mathrm{~cm}$ respectively. The water soluble fractions are perhaps most important in toxicity studies as they are readily absorbed into children' s body through the skin. Therefore it is advantageous that water soluble fractions were lowest at most of $5 \mathrm{~cm}$ samples. Due to possible leaching the soluble fractions for $\mathrm{Co}, \mathrm{Ni}$ and $\mathrm{Zn}$ appeared highest at $24 \mathrm{~cm}$. High values of soluble metal fractions for $\mathrm{Cu}$, and $\mathrm{Zn}$ at surface soils have been reported ${ }^{16}$. Results obtained here are not significantly different from those reported in which $\mathrm{Cu}$ and $\mathrm{Zn}$ where higher in the residual fraction ${ }^{17}$.

The trend of decreasing water soluble metal fraction in the rainy season was $\mathrm{Ni}>\mathrm{Co}>\mathrm{Zn}>\mathrm{Cu}>\mathrm{Mn}$. Highest water soluble fraction in the rainy season was observed at $12 \mathrm{~cm}$ for $\mathrm{Mn}, \mathrm{Co}$, and $\mathrm{Ni}$ while $\mathrm{Cu}$ and $\mathrm{Zn}$ had highest values at $24 \mathrm{~cm}$. For most water soluble fractions the change from increasing trend occur just above $12 \mathrm{~cm}$. Ni was however the only metal detected at $12 \mathrm{~cm}$. The average $\mathrm{F} 1$ fractions were lower in the dry season than in the rainy season.

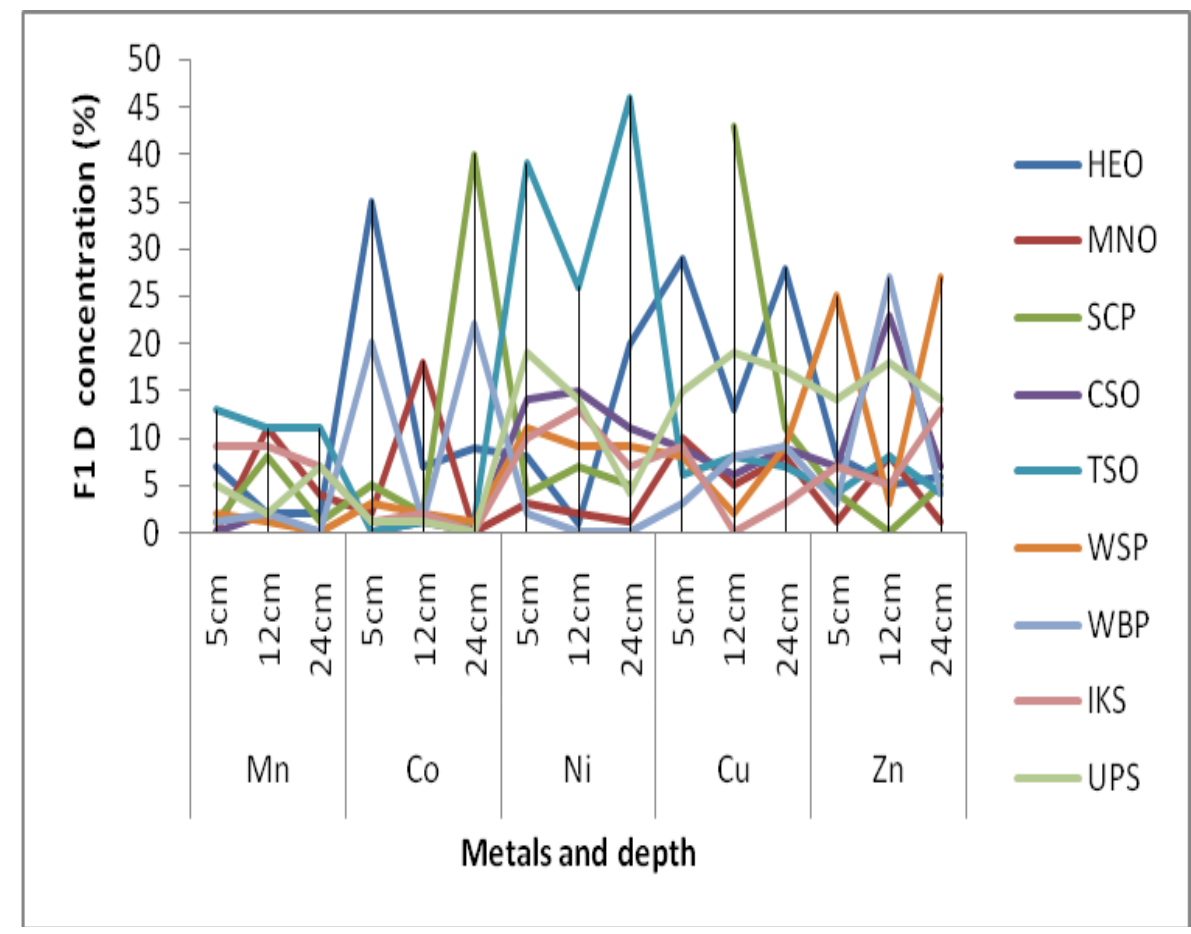

Figure1. Trends of water soluble metal fractions $\left(F_{1}\right)$ and depth in the dry season 
Behavior of Metal Fractions with Depth in Soils of Children's Play Grounds within Owerri Metropolis, Imo State, Nigeria

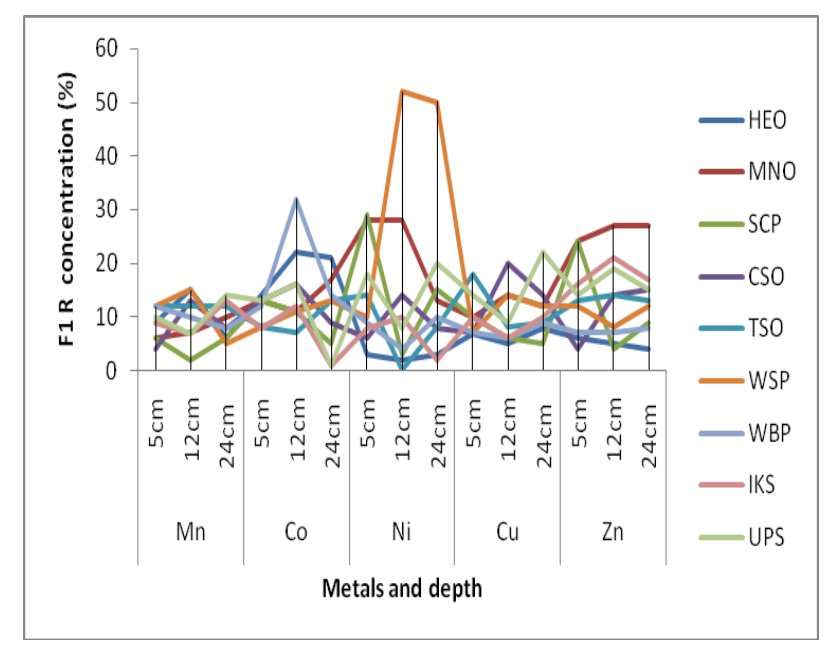

Figure2. Trends of water soluble metal fractions and depth in the rainy season

\subsection{Exchangeable Fraction}

However the exchangeable fractions were highest for $\mathrm{Zn}$ and $\mathrm{Cu}$ at $24 \mathrm{~cm}$, for $\mathrm{Mn}$ and $\mathrm{Co}$ at $5 \mathrm{~cm}$ while Ni exchangeable fraction was highest at $12 \mathrm{~cm}$. The mean values for F2 fractions show a range of 8.11 to $15.89 \%$. Cobalt recorded more undetectable F2 fractions at $24 \mathrm{~cm}$ while Ni and Mn were equally undetected in $\mathrm{F} 2$ at $24 \mathrm{~cm}$. As expected the exchangeable fractions for most metals were generally low irrespectively of the depth. However there was a general decrease with depth with a greater portion occurring between $5 \mathrm{~cm}$ to $12 \mathrm{~cm}$. Osakwe ${ }^{19}$ reported generally low exchangeable metal fractions between $0-15 \mathrm{~cm}$. Therefore this study is in agreement with works elsewhere.

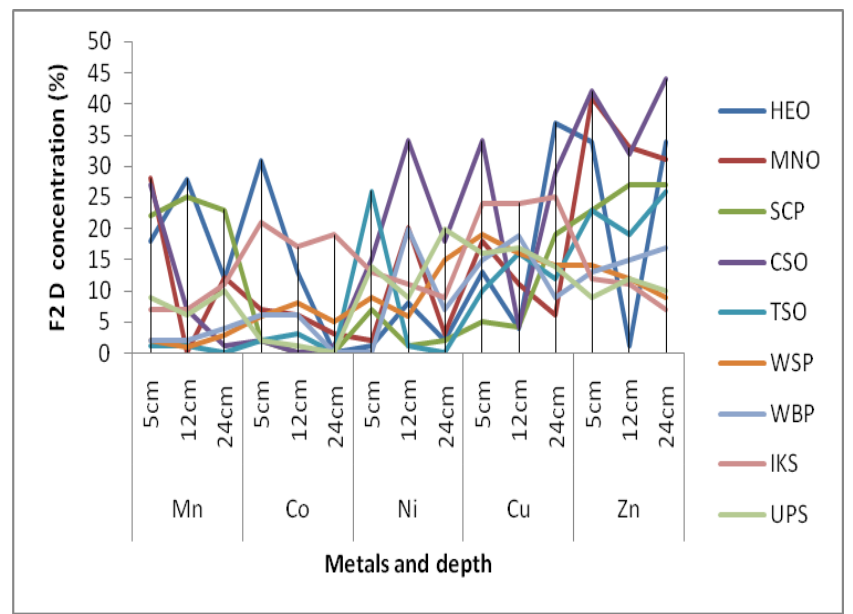

Figure3. Trends of exchangeable fractions $\left(F_{2}\right)$ and depth in the dry season

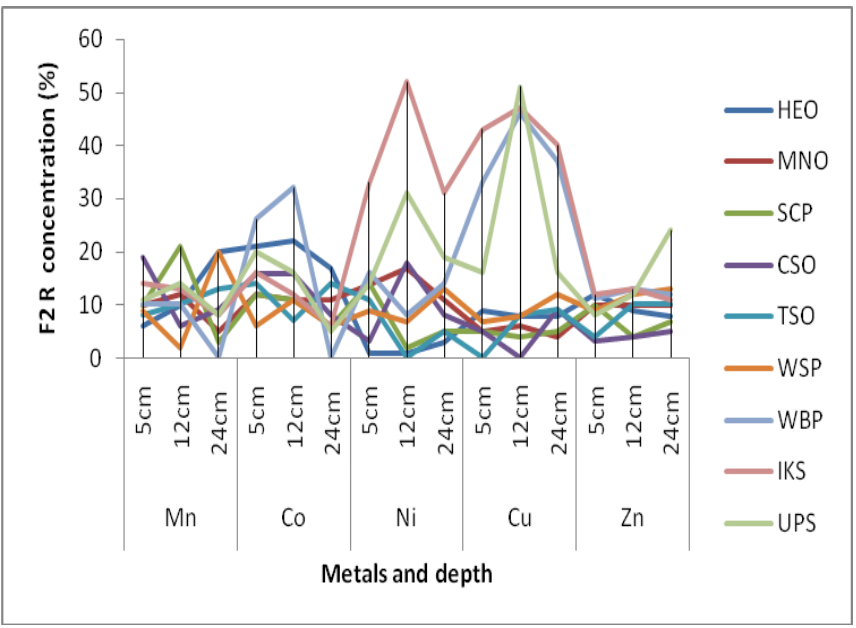

Figure4. Trends of exchangeable fractions $\left(F_{2}\right)$ and depth in the rainy season 
Behavior of Metal Fractions with Depth in Soils of Children's Play Grounds within Owerri Metropolis, Imo State, Nigeria

Values of exchangeable fractions recorded in rainy season (Table 2). This study shows a range of 01 to $52 \%$ except for $\mathrm{Mn}, \mathrm{Co}, \mathrm{Ni}$ and $\mathrm{Cu}$ that showed undetectable exchangeable fractions at varying depth. This range is similar to that reported by Iwegbue ${ }^{20}$. The order of decreasing values was $\mathrm{Ni}>\mathrm{Cu}>\mathrm{Co}>\mathrm{Zn}>\mathrm{Mn}$. It was observed that $\mathrm{Mn}, \mathrm{Co}, \mathrm{Ni}$ and $\mathrm{Cu}$ showed highest values at $12 \mathrm{~cm}$ in the rainy season (fig 4). Highest metal fraction F2 followed the trend of decreasing order $\mathrm{Zn}>\mathrm{Cu}>\mathrm{Ni}>$ $\mathrm{Co}>\mathrm{Mn}$.

\subsection{Organic Bound Fraction}

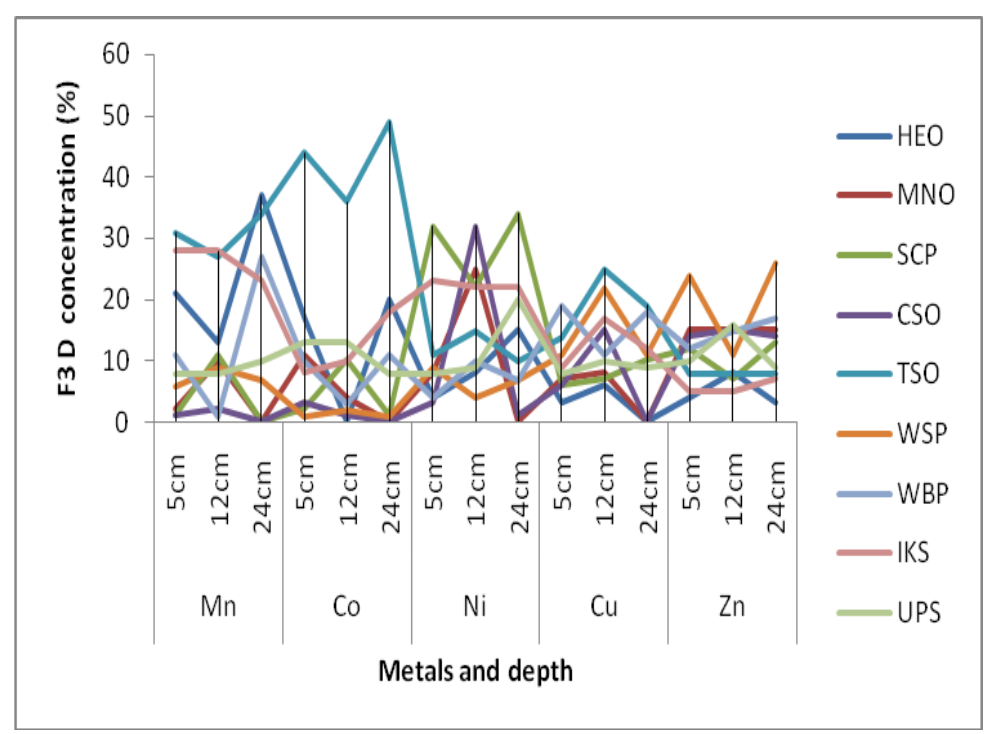

Figure5. Trends of organic bound fractions and depth in the dry season

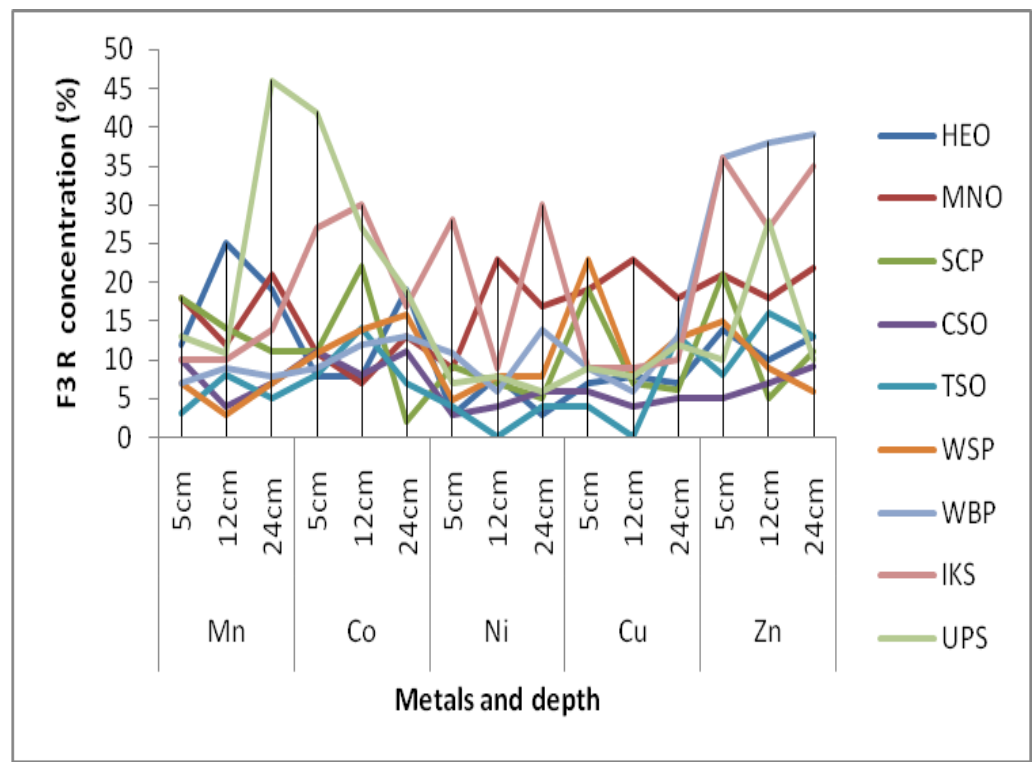

Figure6. Trends of organic bound metal fractions and depth in the rainy season

The mean concentrations were observed to range from 8.87 to $16.33 \%$. The highest metal fraction occurred at TSO $(49 \%)$. In the raining season the mean organically bound metal fractions ranged from 8.1 to $18.44 \%$. The order of decreasing fraction was $\mathrm{Co}>\mathrm{Mn}>\mathrm{Ni}>\mathrm{Zn}>\mathrm{Cu}$. The highest organically bound metal fraction was observed at $24 \mathrm{~cm}$ for $\mathrm{Mn}, \mathrm{Co}, \mathrm{Ni}$ and $\mathrm{Zn}$ while $\mathrm{Cu}$ exhibited highest F3 fraction at $12 \mathrm{~cm}$. Only playground TSO recorded undetected F3 fractions for $\mathrm{Ni}$ and $\mathrm{Cu}$ both at $12 \mathrm{~cm}$.

\subsection{Carbonate Bound Fraction}

In the dry season $\mathrm{Mn}$ in the carbonate bound fractions were within the range 1 to $39 \%$ with the highest found at playground TSO. The acid bound fractions as this F4 is sometimes called would 
Behavior of Metal Fractions with Depth in Soils of Children's Play Grounds within Owerri Metropolis, Imo State, Nigeria

imply that the metal fractions become soluble since the soil $\mathrm{pH}$ is likely acidic as depth increases. Therefore most playgrounds soil samples at $5 \mathrm{~cm}$ had detectable carbonate bound fractions. The order of decreasing F4 fraction was generally $\mathrm{Co}>\mathrm{Zn}>\mathrm{Mn}>\mathrm{Cu}>\mathrm{Ni}$ with their highest concentrations found at varying depths with $\mathrm{Co}$ and $\mathrm{Ni}$ at $5 \mathrm{~cm}, \mathrm{Cu}$ and $\mathrm{Ni}$ at $24 \mathrm{~cm}$ and $\mathrm{Zn}$ at $12 \mathrm{~cm}$. The mean values of F4fractions for dry season ranged from 8.22 to $19.78 \%$.

In the rainy season the range of carbonate bound fraction was 1 to $36 \%$ with highest at WBP for Mn whereas the mean values were from 7 to $17.33 \%$. But the order of decreasing carbonate bound fraction for various metals was $\mathrm{Ni}>\mathrm{Mn}>\mathrm{Cu}>\mathrm{Zn}>\mathrm{Co}$. All metals showed highest values of carbonate bound fractions at $12 \mathrm{~cm}$ except $\mathrm{Zn}$ at $24 \mathrm{~cm}$. Playground TSO had Co and Ni carbonate bound fractions that were not detected.

\subsection{Fe- Mn Bound Fraction}

They were many undetected values of Fe-Mn bound fractions spread across HEO, MNO, SCP CSO TSO and WSP. However, the range was low compared to other operationally defined fractions.

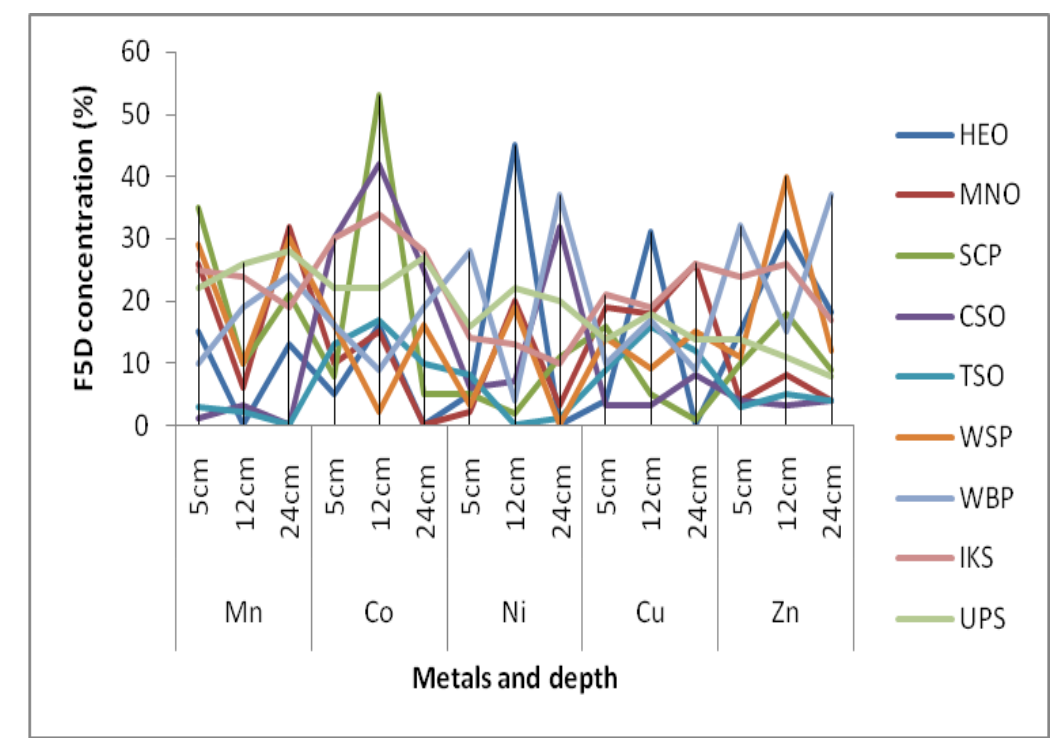

Figure7. Trends of Fe-Mn bound fractions and depth in the dry season

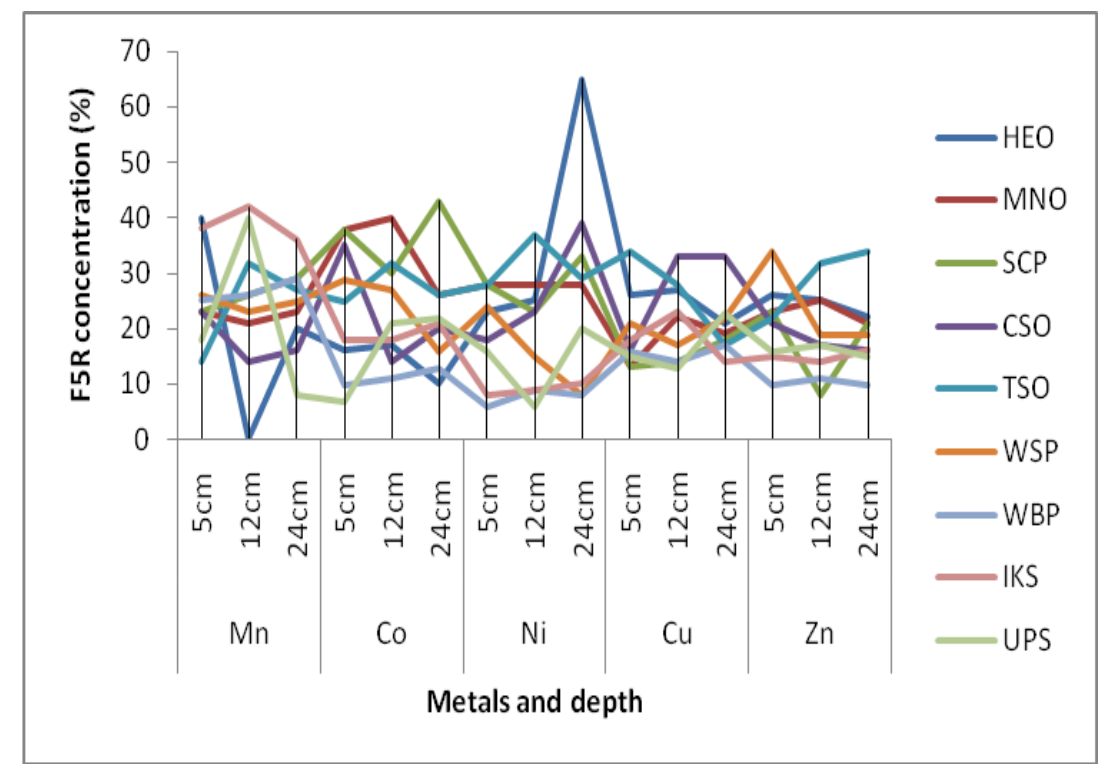

Figure8. Trends of Fe-Mn bound metal fractions and depth in the rainy season

The highest Fe-Mn bound fraction was recorded for HEO (45\%) for the metal Ni. This is not strange as Ni has been reported to be associated with Fe-Mn oxides. The order of decreasing Fe-Mn bound metal fractions was $\mathrm{Co}>\mathrm{Ni}>\mathrm{Zn}>\mathrm{Mn}>\mathrm{Cu}$. The mean Fe-Mn bound metal fractions for dry season ranged from 9.67 to $23.33 \%$. The Fe-Mn bound metal fraction showed a higher range in the rainy 
Behavior of Metal Fractions with Depth in Soils of Children's Play Grounds within Owerri Metropolis, Imo State, Nigeria

season (1 to 65\%) than dry season. This differs from expected results however it is the total metal content that is expected to be higher in the dry season. The order of decreasing metal fraction was Ni $>\mathrm{Co}>\mathrm{Mn}>\mathrm{Zn}>\mathrm{Cu}$ with all highest values recorded at $12 \mathrm{~cm}$ except for $\mathrm{Zn}$ at $24 \mathrm{~cm}$. The mean values ranged from 18.67 to $26.67 \%$. However at $12 \mathrm{~cm} \mathrm{Mn}$ and Co were undetected at HEO and MNO respectively.

\subsection{Residual Fraction}

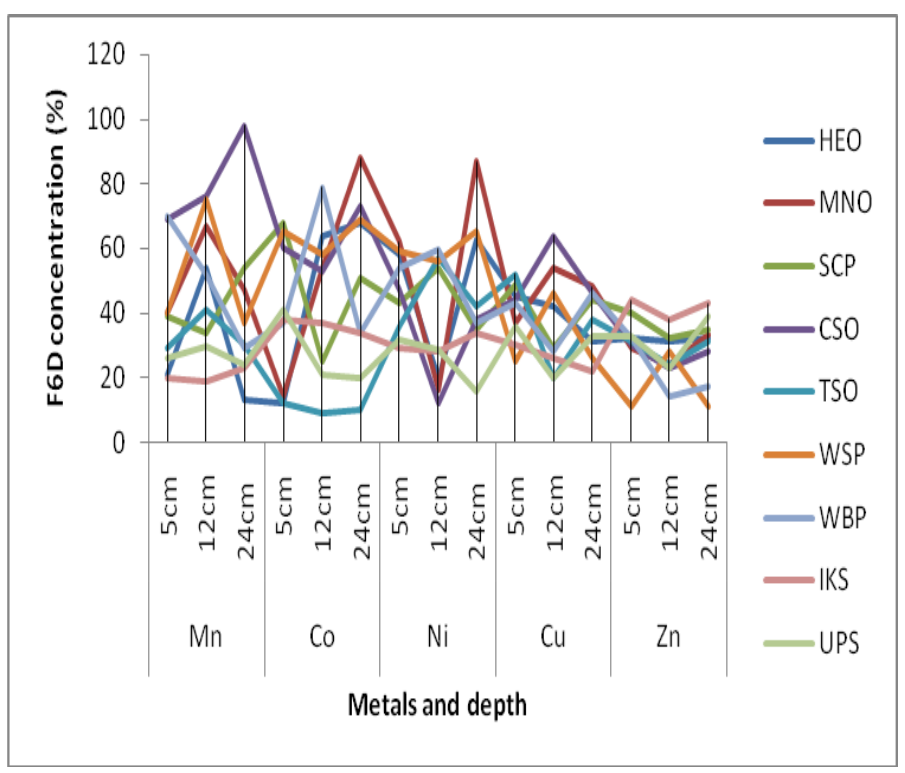

Figure9. Trends of Residual metal fractions and depth in the dry season

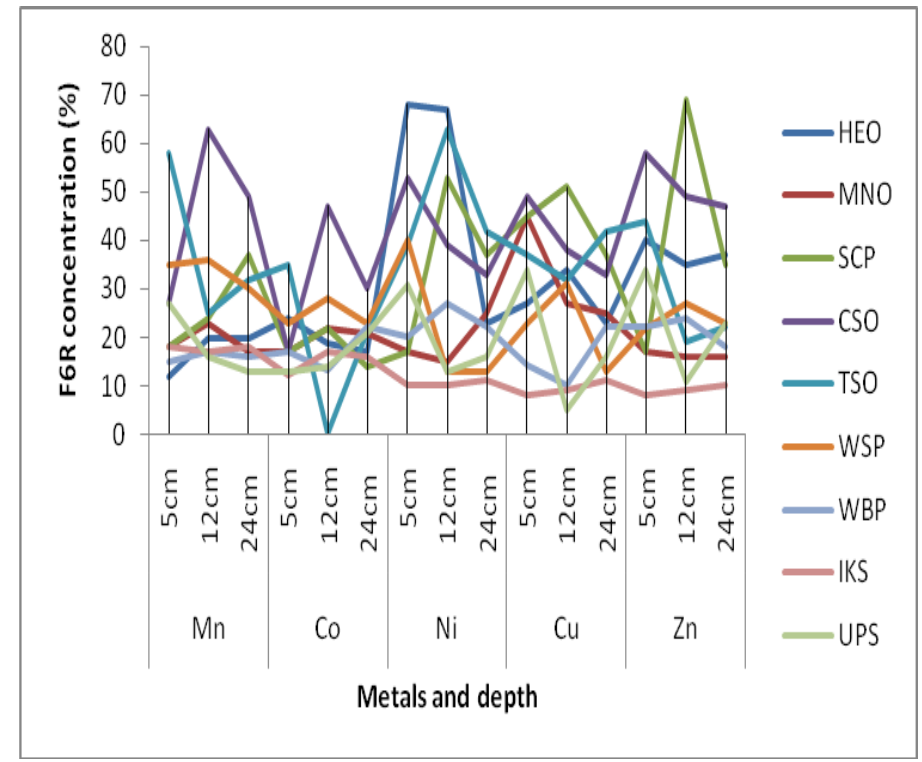

Figure10. Trends of Residual metal fractions and depth in the rainy season

The mean values were ranging from 26.33 to 49.78 and 20.22 to $33.33 \%$. The residual fractions were most prominent for all metals and for all seasons. However, the dry season residual fractions were usually higher than those in the raining season. This may not pose any health risk because the residual fraction is usually much less available.

The residual fraction has been reported widely as the most abundant fraction ${ }^{21,22}$. This fraction range was from 9 to $98 \%$. Despite the wide range most fractions were above $20 \%$, hence the importance of the residual fractions. The highest concentrations of these fractions were found at $12 \mathrm{~cm}$ except for $\mathrm{Zn}$ at $5 \mathrm{~cm}$ and so the order of decreasing fractional concentration was $\mathrm{Mn}>\mathrm{Co}>\mathrm{Ni}>\mathrm{Cu}>\mathrm{Zn}$. The range of residual metal fraction (Table 2) in the rainy season was lower ranging from 05 to $67 \%$. The order of decreasing residual metal fraction is $\mathrm{Zn}>\mathrm{Ni}>\mathrm{Mn}>\mathrm{Cu}>\mathrm{Co}$. The highest values of these fractions were found in $12 \mathrm{~cm}$ except $\mathrm{Ni}$ that had both high values at 5 and $12 \mathrm{~cm}$. 


\section{CONCLUSION}

Metal fractions varied widely with depth often showing significant difference at $12 \mathrm{~cm}$. The results of vertical distribution showed that the heavy metal concentrations were generally higher at the top soil than the sub and bottom soils. This is expected since the top soil is the point of contact from anthropogenic activities. The residual fractions were dominant for most metals though metal fractions showed varying trends at various playgrounds. Dry season fractions were usually higher than same metal fraction in the rainy season.

\section{ACKNOWLEDGEMENT}

This work is part of corresponding author' $\mathrm{s} \mathrm{PhD}$ thesis in the Department of Pure and Industrial Chemistry, University of Port Harcourt. We thank all the numerous persons for their assistance during this research work.

\section{REFERENCES}

[1] Annao, W.L; Nurdans, D.A.K, Cheung, CC Mingh, W., Heavy Metals Concentrations of Surface Dust from Waste Recycling and Its Human Health Implications in Southeast China. Environ. Sc. \& Tech. 42, (7), 2671- 2680 (2008).

[2] Centers for Disease Control and Prevention. Preventing Lead Poisoning in Young Children; Centers for Disease Control: Atlanta, GA, 2005.

[3] Khashman O.A. Determination of metal accumulation in deposited street dusts in Amman, Jordan, Environmetal Geochemistry and Health, 29 (1), 1-10, (2007).

[4] Verla E.N, Verla A.W, Ugwulor L. Seasonal variation of heavy metals in playgrounds of public schools within Owerri metropolis, Imo state, Nigeria, International Letters of Chemistry, Physics and Astronomy, 50: 61-70, 2015.

[5] Verla E.N, Verla A.W., Horsfall M Jr., Spiff A.I., Assessment of some heavy metal in children's playgrounds in Owerri metropolis, Imo state, Nigeria, Journal of Chemical Society of Nigeria, 50, 1-6, 2015.

[6] F.J Higgs, H.W. Mielke and M. Brisco, Soil lead at elementary public schools: Comparison between schools properties and residential neighborhoods of New Orleans, Environ. Geochem. Health, 21, 27-36, 1997

[7] V. O. Ajibolo, and I. Ozigis. Partitioning of some heavy metals in Kaduna streets soils, Journal of Chemical Society of Nigeria. 30 (1), 62 - 66, 2005.

[8] W.L Annao,; Nurdans, D.A.K, Cheung, CC Mingh, W. Heavy Metals Concentrations of Surface Dust from e-Waste Recycling and Its Human Health Implications in Southeast China, Environmental science \& technology, 42 (7), 2671-2680, 2008.

[9] Popoola O.E, Bamgbose, O Okonkwo, Arowolo, O.J; Odukoya T.A and Popoola, A.O.Heavy Metals Content in Playground Topsoil of Some Public Primary Schools in Metropolitan Lagos, Nigeria, Research Journal of Environmental and Earth Sciences, 4(4), 434-439, 2012.

[10] Li, X. D..; Poon, C. S.; Liu, P. S. Heavy metal contamination of urban soils and street dusts in HongKong, Applied Geochemistry,16, 1361- 1368, 2001.

[11] Adamu, U. U.; Sani, S. S.; Mohammed, A. Hamza and J. O. Oluwole. Seasonal Chemical Fractionation of metals in some dumpsites, Journal of Environmental and Earth Science, 3 (2), 1-8, 2013.

[12] Onweremadu E.U. J.U. Amaechi and B.N. Ndukwu, Vertical Distribution of Cadmium and Lead on Soils Affected by Metropolitan Refuse Disposal in Owerri, Southeastern Nigeria, Iranica Journal of Energy \& Environment, 2 (1), 62-67, 2011.

[13] Orisakwe O. E., Nduka, J. K. , Amadi, C. N., Dike, D.O. and Bede, O. Heavy metals health risk assessment for population via consumption of food crops and fruits in Owerri, South Eastern, Nigeria, Chemistry Central Journal, 67-77, 2012.

[14] Ljung K.O. Schinus and E. Otabbong, Metal in soil of children' s Urban environment in the small northern European city of Uppsala, Science of the Total Environment, 366 (2-3), 749 - 759, 2006.

[15] Binggan W. J. Fengging L. Xumei and M. Schuyong, Heavy metal inducd ecological risk in the city of Urumq, NWchina," Environmental Assessments, 160, 33-45, 2010.

[16] Osakwe S.A., Chemical speciation and mobility of some heavy metals in soils around automobile waste dumpsites in Northern part of Niger Delta, South Central Nigeria, Journal of Appllied Science and Environment. Manage, 14 (4), 123-130, 2010. 
Behavior of Metal Fractions with Depth in Soils of Children's Play Grounds within Owerri Metropolis, Imo State, Nigeria

[17] Taofeek A. Y and Tolulope O. O. Evaluation of some Heavy Metals in Soils along a Major Road in Ogbomoso, South West Nigeria, Journal of Environmental and Earth Sciences, 2 (8), 71-79, 2012.

[18] Uba S., Uzairu A. and Okunola O. J. Content of heavy metals in Lumbricus Terrestris and associated soils in dump sites, International Journal of Environmental Research, 3(3), 353 - 358, 2009.

[19] Uba S., Uzairu A., Harrison G. F. S., Balarabe M. L. and Okunola O. J. Assessment of heavy metals bioavailabilty in dumpsites of Zaria metropolis, African Journal Biotechnology, 7(2), 122-130, 2008.

[20] Okorokwo N. E., Igwe J. C. and Onwuchekwe E. C. Risk and health implication of polluted soils for crops production, African Journal of Biotechnology, 4(13), 1521 - 1524, 2005.

[21] Awokunmi E. E., Asaolu S. S. and Ipinmoroti K. O. Effect of Leaching on heavy metal concentrations of soil in some dumpsites, African Journal Environment and Technology, (8), 495 - 499, 2010.

[22] Horsfall M. (Jnr.) and Spiff A.I. Speciation and bioavailability of heavy metals in sediment of Diobu River, Port Harcourt, Nigeria, European Journal Science Research, 6(3), 20-36, 2005.

Citation: Verla Evelyn Ngozi, et.al, "Behavior of Metal Fractions with Depth in Soils of Children's Play Grounds within Owerri Metropolis, Imo State, Nigeria”, International Journal of Advanced Research in Chemical Science, vol. 6, no. 12, p. 24-33, 2019. DOI: http://dx.doi.org/10.20431/2349-0403.0612004

Copyright: (C) 2019 Authors. This is an open-access article distributed under the terms of the Creative Commons Attribution License, which permits unrestricted use, distribution, and reproduction in any medium, provided the original author and source are credited. 